\title{
THE EFFECT OF DIFFERENT PHYSIOTHERAPY PROGRAMS ON FUNCTIONAL STATUS AND QUALITY OF LIFE IN PATIENTS WITH NECK PAIN
}

\author{
Silvija Reimerytė, PT, Eglè Ieva Jamontaitè, PT.
}

Centre of Rehabilitation, Physical and Sports Medicine, Vilnius University Hospital, Santaros Klinikos

Introduction. As a result of modern sedentary lifestyle more and more people of working age are complaining of neck and shoulder pain.

Purpose. To compare the effect of two different physiotherapy programs of patients having cervical spine pain.

Methods Back-check by Dr. Wolff equipment, inclinometer, visual analog scale for pain, Oswestry Disability Index (ODI), Neck Disability Index (NDI).

Results: The research showed significant increase $(p<0.05)$ in isometric neck and shoulder muscle strength (Table 1 ), neck range of motion and pain intensity in both case and control groups after different physiotherapy programs were applied. The obtained values of the ODI (Chart 1) and NDI (Chart 2) were also significant $(p<0.05)$. On the basis of a comparison between the case group and the control group statistically significant correlations $(p<0.05)$ were determined after evaluating the following parameters: isometric muscle strength of left-right shoulder abduction, pain intensity based on NDI, as well as reading.

Table 1. Isometric neck and shoulder muscle strength.

\begin{tabular}{|l|c|c|c|c|c|}
\hline \multirow{2}{*}{} & \multicolumn{2}{c}{$\begin{array}{c}\text { Case group } \\
\text { (mean } \pm \text { SD) }\end{array}$} & \multicolumn{2}{c|}{$\begin{array}{c}\text { Control group } \\
\text { (mean } \pm \text { SD) }\end{array}$} & \multirow{2}{*}{ p } \\
\cline { 2 - 5 } & Before PT & After PT & Before PT & After PT & \\
\hline & $7,2 \pm 3,6$ & $10,0 \pm 3,5^{*}$ & $5,4 \pm 2,1$ & $9,1 \pm 3,3^{*}$ & 0,395 \\
\hline Neck flexor & $9,0 \pm 4,4$ & $14,6 \pm 5,4^{*}$ & $8,3 \pm 3,3$ & $13,6 \pm 4,9^{*}$ & 0,523 \\
\hline Neck extensor & $7,1 \pm 2,5$ & $10,9 \pm 3,3^{*}$ & $6,9 \pm 2,8$ & $10,4 \pm 3,0^{*}$ & 0,587 \\
\hline $\begin{array}{l}\text { Neck side bending } \\
\text { left }\end{array}$ & $7,4 \pm 2,9$ & $11,1 \pm 3,5^{*}$ & $6,9 \pm 2,2$ & $10,3 \pm 3,1^{*}$ & 0,403 \\
\hline $\begin{array}{l}\text { Neck side bending } \\
\text { right }\end{array}$ & Shoulder muscle isometric strength (kg) & & \\
\hline & $43,5 \pm 16,1$ & $53,4 \pm 16,2^{*}$ & $35,8 \pm 12,9$ & $43,7 \pm 14,4^{*}$ & 0,053 \\
\hline \begin{tabular}{l} 
Upper body push \\
\hline Upper body pull
\end{tabular} & $43,8 \pm 15,3$ & $49,7 \pm 16,2^{*}$ & $35,3 \pm 14,2$ & $43,1 \pm 16,1^{*}$ & 0,202 \\
\hline Left shoulder abduction & $14,8 \pm 7,5$ & $20,4 \pm 8,4^{*}$ & $9,4 \pm 4,4$ & $14,4 \pm 5,6^{*}$ & 0,011 \\
\hline $\begin{array}{l}\text { Right shoulder } \\
\text { abduction }\end{array}$ & $14,9 \pm 7,1$ & $20,9 \pm 8,3^{*}$ & $9,5 \pm 3,5$ & $14,5 \pm 3,8^{*}$ & 0,003 \\
\hline
\end{tabular}

SD - standard deviation, PT - physiotherapy, $*-p<0,05$ in groups, $\mathrm{p}$-independent $\mathrm{t}$-test between groups.

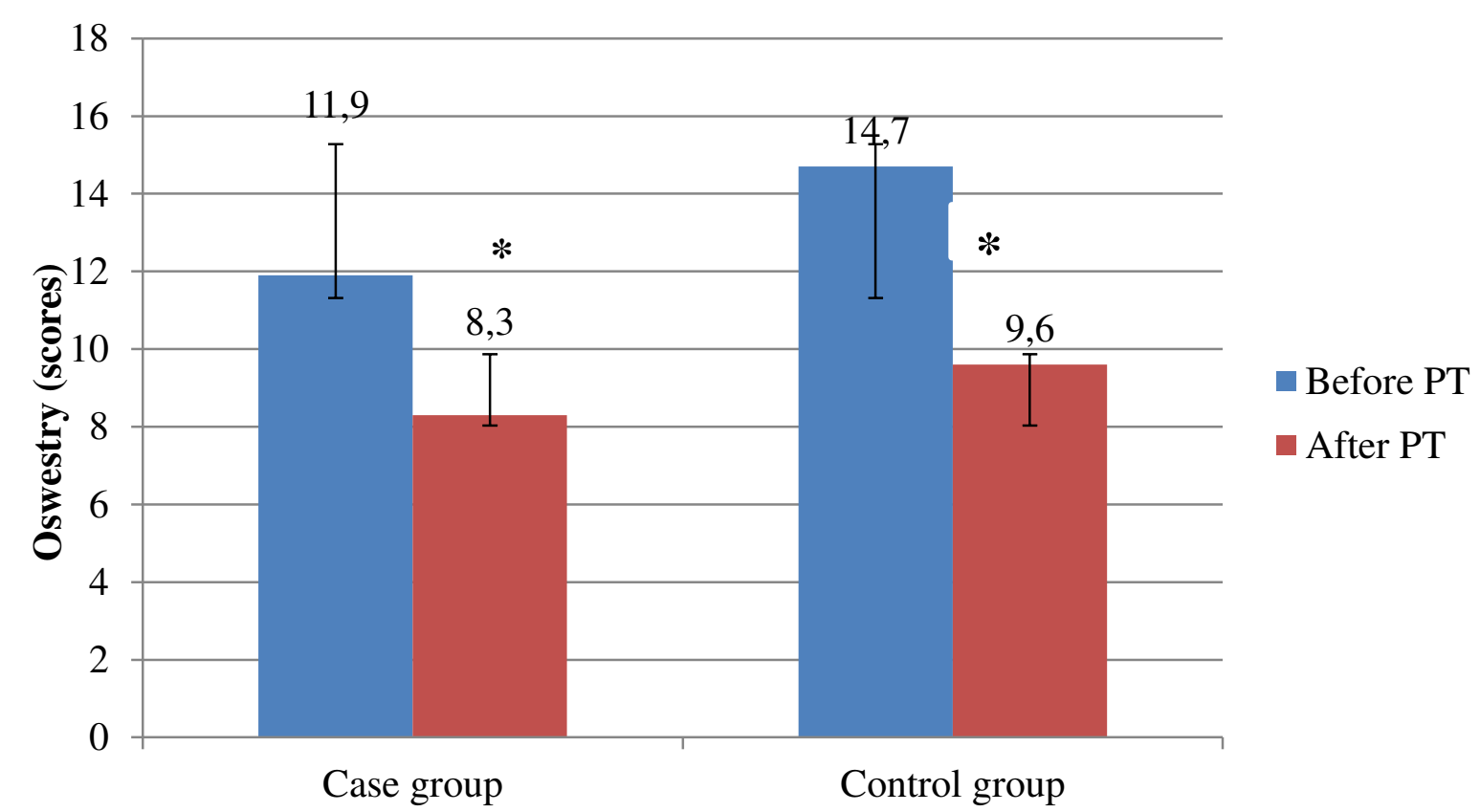

Chart 1. Values of the Oswestry Disability Index.

* - $\mathrm{p}<0,05, \mathrm{PT}-$ physiotherapy.

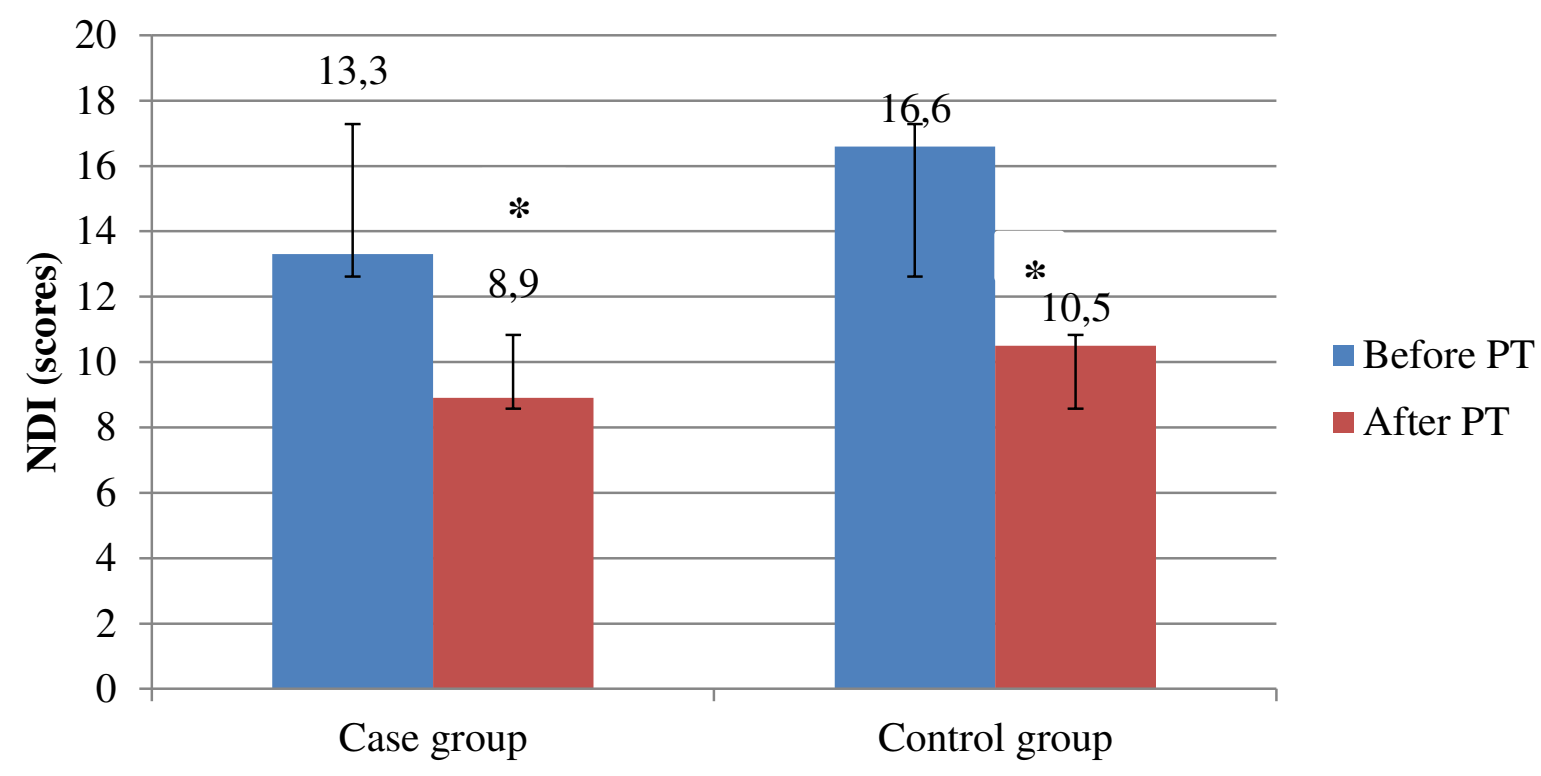

Chart 2. Values of the Neck Disability Index.

NDI - Neck Disability Index, * $-p<0,05$, PT - physiotherapy.

\section{Conclusions.}

1. Both physiotherapy with Dr. Wolff equipment and dynamic exercises proved to be an effective means of increasing the isometric strength of neck and shoulder muscles $(p<0.05)$. However, isometric exercises and exercises with Dr. Wolff equipment were more effective for strengthening the isometric strength of muscles involved in shoulder abduction $(p<0.05)$.

2. Just like dynamic exercises, isometric exercises and exercises with Dr. Wolff equipment were found to significantly improve neck range of motion and to decrease neck and shoulder pain $(p<0.05)$.

3. Statistically reliable results were obtained when assessing the ODI and the NDI after different physiotherapy programs $(p<0.05)$. Analyzing the section scores of NDI questionnaire, statistically significant results $(p<0.05)$ between the two groups were determined after evaluating the following parameters: reading of the group, which performed isometric exercises and exercises with Dr. Wolff equipment; pain intensity of the group, which performed dynamic exercises for strengthening neck and shoulder muscles. 